Este é um artigo publicado em acesso aberto sob uma licença Creative Commons https://creativecommons.org/licenses/by-nc/4.0/

\title{
A participação dos servidores técnico-administrativos na avaliação institucional: o que dizem os relatórios autoavaliação institucional
}

\author{
Joice da Costa Martins ${ }^{1}$ \\ Jorge Luiz Lordelo de Sales Ribeiro ${ }^{2}$
}

Resumo: O presente artigo buscou compreender como ocorre a participação dos servidores TécnicoAdministrativos em Educação (TAE) na avaliação institucional das universidades federais brasileiras, a partir da perspectiva dos Relatórios de Autoavaliação Institucional elaborados pelas Comissões Próprias de Avaliação (CPA). A amostra da pesquisa foi composta pelas cinco universidades federais melhor conceituadas no Índice Geral de Cursos (IGC) de 2014, uma por região do país, sendo selecionadas a Universidade Federal do Pará (UFPA), a Universidade Federal de Pernambuco (UFPE), a Universidade de Brasília (UNB), a Universidade Federal de Minas Gerais (UFMG), e a Universidade Federal do Rio Grande do Sul (UFRGS). Os trechos dos relatórios onde os servidores TAE são mencionados foram identificados através da utilização de descritores estabelecidos previamente, transcritos e examinados segundo a análise categorial proposta por Bardin (2011). Os resultados encontrados revelaram que, ao contrário do que indicam os princípios estabelecidos pelo Sistema Nacional de Avaliação da Educação Superior (Sinaes) e do que recomenda a literatura, existe pequena participação efetiva dos servidores TAE na avaliação institucional das universidades federais brasileiras.

Palavras-chave: Avaliação institucional. Servidores técnico-administrativos em educação. TAE. Universidades federais. Sinaes.

\section{The participation of the technical-administrative staff in education in the institutional Evaluation: what the reports say institutional self-evaluation}

Abstract: The present article sought to understand how the participation of the Technical-Administrative Staff in Education (TAE) in the institutional evaluation of Brazilian federal universities occurs, from the perspective of the Institutional Self-Assessment Reports prepared by the Self-Appraisal Committees CPA. The research sample was composed of the five federal universities that are best rated in the General Index of Courses (IGC) of 2014, one per region of the country, then was selected the Federal University of Pará (UFPA), Federal University of Pernambuco (UFPE), University of Brasília (UNB), the Federal University of Minas Gerais (UFMG), and the Federal University of Rio Grande do Sul (UFRGS). The excerpts from the reports where the 'TAE' are mentioned were identified using descriptors previously established, transcribed and analyzed. The results showed that, contrary to the principles established by the National System for the Evaluation of Higher Education (SINAES) and what the literature recommends, there is no effective participation of TAE in the institutional evaluation of Brazilian federal universities.

Key words: Institutional evaluation. Technical-administrative staff in education. TAE. Federal universities. Sinaes. 


\section{Introdução}

Ao estudar a estruturação do sistema de ensino superior no Brasil, especialmente a partir da Reforma Universitária de 1968, é possível perceber que a avaliação institucional vem ganhando importância ao longo do tempo e se consolidando como um dos instrumentos que auxilia na construção de suas políticas.

O interesse pelo assunto passou a ganhar efetivo destaque no início da década de 1980, quando o forte crescimento do número de Instituições de Ensino Superior (IES) e o consequente aumento no número de matrículas fizeram emergir a preocupação com a qualidade dessas IES e do ensino por elas ofertado. Neste contexto e por iniciativa do Conselho Federal de Educação (CFE) surgiu, em 1983, o Programa de Avaliação da Reforma Universitária (Paru). O Paru foi desenvolvido tomando como fonte primária o texto "Programa de Avaliação da Reforma Universitária", de autoria do Grupo Gestor designado pelo CFE e publicado na Revista Educação Brasileira, editada pelo Conselho de Reitores das Universidades Brasileiras (CRUB), e tinha o propósito de identificar as circunstâncias nas quais se davam a produção e difusão do conhecimento do sistema de educação superior. (BARREYRO; ROTHEN, 2008).

Apesar do seu aparente fracasso, pois não chegou a apresentar seus resultados e foi desativado um ano depois, o Paru serviu para despertar a comunidade acadêmica para a importância do tema, configurando-se como precursor das experiências de avaliação da educação superior brasileira que viriam nos anos seguintes.

No ano de 1985, em nova tentativa de implementar a avaliação institucional nas universidades, o Ministério da Educação (MEC) criou a Comissão Nacional de Reformulação da Educação Superior, conhecida como a Comissão de Notáveis, que apresentou relatório onde apontava a ausência de parâmetros para a alocação de recursos públicos como um dos mais graves problemas do ensino superior brasileiro. A comissão sinalizou que a avaliação do ensino superior deveria contemplar " [...] avaliação dos cursos, avaliação dos alunos; avaliação dos professores; avaliação didático-pedagógica do ensino; avaliação de servidores técnicos e administrativos; e avaliação das carreiras" (ZAINKO, 2008, p. 829).

O relatório final desta comissão foi o ponto de partida para os trabalhos do Grupo Executivo para a Reforma da Educação Superior (GERES), grupo interno do MEC constituído em 1986 que, sustentado numa concepção regulatória, apresentou uma nova proposta de avaliação. Este modelo fazia contraponto à autonomia das IES, dando prioridade às dimensões individuais (do alunado, dos cursos e das instituições), e utilizando seus 
A participação dos servidores técnico-administrativos na avaliação institucional: o que dizem os relatórios autoavaliação institucional

resultados para o controle da qualidade das instituições (públicas ou privadas), comprometendo a alocação de recursos públicos, que passariam a ser prioritariamente direcionados aos "Centros de Excelência” (BARREYRO; ROTHEN, 2008; INEP, 2007).

O projeto foi profundamente criticado por professores, funcionários e estudantes, que temiam a desobrigação do governo com o suprimento de recursos às universidades, bem como a perda de sua força política. Esta impopularidade da proposta fez com que o governo retirasse o anteprojeto do Congresso Nacional, mantendo as ideias ali presentes como norteadoras de sua política geral. O modelo apresentado pelo GERES também desencadeou várias discussões na comunidade acadêmica, estimuladas, principalmente, por entidades como a Associação Nacional de Docentes (ANDES) e o Conselho de Reitores das Universidades Brasileiras (CRUB) (CUNHA, 1997)

No início da década de 1990, atendendo às demandas da comunidade acadêmica, foi criada a Comissão Nacional de Avaliação das Universidades Brasileiras. Diferente das anteriores, que reuniam "notáveis", esta comissão era composta por membros de entidades representativas da educação superior, e tinha o intuito de "estabelecer diretrizes e viabilizar a implementação do processo de avaliação institucional nas universidades brasileiras" (BARREYRO; ROTHEN, 2008). O trabalho desta comissão deu origem ao Programa de Avaliação Institucional das Universidades Brasileiras (PAIUB) que, segundo Zainko (2008), era um modelo de participação voluntária no qual cabia ao MEC estimular a adesão das instituições a esta prática avaliativa, colocando-se como articulador e financiador do processo.

Norteado por princípios como globalidade, comparabilidade, respeito à identidade institucional, não punição ou premiação, adesão voluntária, legitimidade e continuidade, o PAIUB concebia a autoavaliação como etapa inicial de um processo que se completava com a avaliação externa, estabelecendo uma nova relação com o conhecimento e com a formação, através do diálogo com a sociedade e a comunidade acadêmica (BARREYRO; ROTHEN, 2008; INEP, 2007). Entendendo a educação como bem público e colocando a sua avaliação sob controle da sociedade e da própria comunidade acadêmica, o PAIUB “[...] aposta na construção de práticas avaliativas que sejam participativas, contínuas e sistemáticas, afinadas com o debate público e com a função social da educação superior no momento histórico", como observa Zainko (2008, p. 829). Embora tenha conseguido dar legitimidade à cultura avaliativa e propiciado transformações nítidas à dinâmica das IES, além de receber ampla adesão das universidades brasileiras, a interrupção do apoio do MEC a transformou tãosomente num processo de avaliação interno e determinou sua curta existência (INEP, 2007). 
Com o fim do PAIUB e atendendo à premissa de reduzir o papel do Estado na oferta de educação superior, sem tirar dele o controle sobre o mesmo, foi constituído um sistema avaliativo fortemente baseado na averiguação dos produtos educacionais, com a intenção de mensurar em que medida os conhecimentos eram adquiridos pelos estudantes e comparar o desempenho das diferentes instituições (ZAINKO, 2008). Alicerçado na Lei nº 9.131/1995, que restabelece o papel do MEC, e na Lei $n^{\circ}$ 9.394/1996, Lei de Diretrizes e Bases da Educação Nacional (LDB), novos mecanismos de avaliação começaram a ser gradativamente implementados, sendo o principal deles o Exame Nacional de Cursos (ENC), que consistia na realização anual de um exame para aferir os conhecimentos e competências adquiridos pelos estudantes na fase final dos cursos de graduação, e ficou conhecido como "provão".

De caráter totalmente quantitativo, obrigatório e regulador, e a serviço dos interesses do mercado, o ENC tinha ênfase sobre a dimensão de ensino e função classificatória permitindo que, a partir de uma lógica onde a qualidade de um curso era diretamente proporcional ao nível de conhecimento que seus alunos conseguiam demonstrar no exame, permitia a comparabilidade entre as performances das diferentes instituições (DIAS SOBRINHO, 2003; INEP, 2007), modelo criticado por Dias Sobrinho (1996, p. 21), que afirma que:

A avaliação não deve servir de organizador social das instituições, também não de indivíduos e grupos, não deve se oferecer como instrumento pretensamente neutro e técnico a justificar e subsidiar as políticas de alocação (ou de "desalocação"?) de recursos orçamentários, muito menos deve ser mecanismo de controle, exclusão, opressão ou punição de uns e premiação ou favorecimento de outros.

Em 2002, com as mudanças nas concepções e políticas de educação superior, foi constituída a Comissão Especial da Avaliação da Educação Superior (CEA), composta por renomados professores de diversas universidades brasileiras, objetivando "analisar, oferecer subsídios, fazer recomendações, propor critérios e estratégias para a reformulação dos processos e políticas de avaliação da Educação Superior e elaborar a revisão crítica dos seus instrumentos, metodologias e critérios utilizados" (INEP, 2007, p. 13). O documento síntese dos estudos desta comissão, intitulado "Sistema Nacional de Avaliação da Educação Superior - Sinaes: bases para uma nova proposta da educação superior", foi construído com a partir de um conceito de avaliação centrado em ideias de integração e participação, consideradas “conceitos fundamentais para a construção de um sistema de avaliação capaz de aprofundar os compromissos e responsabilidades sociais, [...] promover os valores democráticos, o respeito à diversidade, a busca da autonomia e a afirmação da identidade.” (INEP, 2007, p. 87). 
A participação dos servidores técnico-administrativos na avaliação institucional: o que dizem os relatórios autoavaliação institucional

Leite (2005 apud RIBEIRO, 2015, p. 147) classifica os diversos tipos de avaliação, dentre as quais se encontra o modelo de avaliação emancipatória ou participativa que, segundo Saul (2008), é um paradigma que inclui conceitos de emancipação, decisão democrática, transformação e crítica educativa, e se caracteriza pela utilização de métodos dialógicos e participantes. Nas palavras de Dias Sobrinho (1996, p. 23), “[...] a avaliação busca conhecer não para execrar o passado, punir o presente e condenar o futuro, mas, para compreender as dificuldades e equívocos e potenciar as condições de construir com melhor qualidade os agentes, a instituição e os contextos".

$\mathrm{O}$ documento, produzido pela CEA, deu origem à Lei ${ }^{\circ} 10.861$, de 04 de abril de 2004, que institui o Sistema Nacional de Avaliação da Educação Superior (Sinaes), que tem como finalidades:

[...] a melhoria da qualidade da educação superior, a orientação da expansão da sua oferta, o aumento permanente da sua eficácia institucional e efetividade acadêmica e social e, especialmente, a promoção do aprofundamento dos compromissos e responsabilidades sociais das instituições de educação superior, por meio da valorização de sua missão pública, da promoção dos valores democráticos, do respeito à diferença e à diversidade, da afirmação da autonomia e da identidade institucional (BRASIL, 2004).

$\mathrm{Na}$ concepção de Demo (2010, p. 32), “qualidade define-se como horizonte de participação política". Assim, compreendendo que qualidade é participação, podemos considerar que a qualidade da educação superior, em especial nas instituições públicas, é diretamente influenciada pela participação dos seus atores institucionais na sua construção cotidiana. Para o autor, o que está em jogo na avaliação relacionada à qualidade é “[...] a arte da comunidade se autogerir, a criatividade cultural que demonstra em sua história e espera para o futuro, a capacidade de inventar seu espaço próprio, forjando sua autodefinição, sua autodeterminação, sua autopromoção, dentro dos condicionamentos objetivos" (DEMO, 2010, p. 22).

Assim, a avaliação cujo objetivo é a qualidade, passa pela elaboração coletiva e transparente dos critérios, a partir da construção grupal de questionamentos que promovam a ruptura das inércias e coloquem em movimento um conjunto articulado de estudos, análises, reflexões e juízos de valor, com capacidade de proporcionar mudança qualitativa da instituição, em todo o seu contexto, com melhoria nos processos e nas relações psicossociais (DIAS SOBRINHO, 1996).

A avaliação deve assegurar "[...] a participação do corpo discente, docente e técnicoadministrativo das instituições de educação superior, e da sociedade civil, por meio de suas representações." e contemplar, entre outras dimensões, aquela que trata da organização e 
gestão da instituição, seu funcionamento e a representatividade dos seus colegiados, sua independência e autonomia na relação com a mantenedora, e a participação dos segmentos da comunidade acadêmica nos processos decisórios (BRASIL, 2004), o que corrobora os critérios a serem valorizados, sugeridos por Gadotti (2010), trazidos a seguir:

[...] de representatividade, de legitimidade, de participação da base, de planejamento participativo, de convivência, de identidade ideológica, de consciência política, de solidariedade comunitária, de capacidade crítica e autocrítica, de autogestão e de outros elementos que, em última instância, serviriam para desenvolver a cidadania. E conclui: se qualidade é participação, avaliação qualitativa equivale a avaliação participante (GADOTTI, 2010 apud DEMO, 2010, p. 3).

As diversas iniciativas para a implantação da avaliação institucional na educação superior brasileira evidenciam mais do que a relação entre seus propósitos e metodologias e as distintas concepções de educação superior: mostram, também, o envolvimento dos diversos atores institucionais que compõem a comunidade acadêmica. Passear pela história da avaliação institucional no Brasil nos permite perceber o protagonismo do Estado e de algumas entidades representativas relacionadas à categoria docente, em contraponto à falta de envolvimento das categorias técnico-administrativa e discente. Contrariando o que aponta Dias Sobrinho (1996, p. 16) quando afirma que “[...] devem ser tomadas como importantes as distintas perspectivas e as múltiplas dimensões de uma instituição, a diversidade de interesses dos grupos, que constroem sua cotidianeidade [...]", até a edição da lei do Sinaes, nenhum dos projetos propunha claramente a participação efetiva dos servidores técnico-administrativos na avaliação institucional das universidades brasileiras, bem como não se identifica nas leituras feitas nenhum sinal de reivindicação de participação por parte desta categoria.

Neste sentido, o presente trabalho tem o objetivo de compreender como ocorre a participação dos servidores Técnico-Administrativos em Educação (TAE) no processo de avaliação institucional das universidades federais brasileiras, treze anos depois da implementação do Sinaes, a partir da análise dos Relatórios de Autoavaliação Institucional, apresentados por suas Comissões Próprias de Avaliação (CPA).

\section{Participação: do que estamos falando?}

Para compreender como ocorre a participação dos servidores TAE no processo de avaliação institucional das Universidades Federais brasileiras é preliminar e fundamental compreender minimamente o conceito de participação. 
A participação dos servidores técnico-administrativos na avaliação institucional: o que dizem os relatórios autoavaliação institucional

Fausto Neto (1993) afirma que a temática de participação popular é antiga e esteve presente no panorama político brasileiro em diferentes momentos históricos, envolvendo diferentes atores institucionais, em função de interesses diversos e considerando o contexto conjuntural de cada época. Entretanto, o conceito de participação remonta a períodos bem mais antigos, abrigando-se a partir do século XIX "sob as teorias da democracia liberal ou sob os diferentes 'modelos' de democracia" (VIANNA; CAVALCANTI; CABRAL, 2009, p. 228)

O conceito sociológico de participação é empregado para designar "o grau de integração do indivíduo em um grupo, sociedade ou instituição, expresso na intensidade, categoria e natureza dos contatos que mantém com os demais, pressupondo um alto nível de conscientização social e política" (SAYAGO, 2000, p. 41).

\footnotetext{
A democracia (ou a comunidade política justa e legítima) para Rousseau, exige participação. Não apenas a participação de todos na sua criação - esta também - mas a reiteração permanente da vontade geral que igualmente emerge do ato fundante (VIANNA; CAVALCANTI; CABRAL, 2009, p. 231).
}

Rocha e Bursztyn (2005) e Vianna, Cavalcanti e Cabral (2009) concordam que a participação tem sido exercida prioritariamente a partir da representação, quando os grupos sociais, através do voto, elegem representantes a quem são transferidas as funções de discutir e decidir sobre assuntos de interesse coletivo. No entanto, os mesmos autores destacam que "nem todos os atores conseguem se fazer representar pela representação" (ROCHA; BURSZTYN, 2005, p. 47). Além disso "Participação - política e igualitária - e não somente mediante o voto, é o instrumento de poder que o povo possui" (VIANNA; CAVALCANTI; CABRAL, 2009, p. 232).

A participação proporciona a ampliação do exercício da democracia. Entretanto, para Sayago (2000), muitas vezes as classes dirigentes se utilizam desses espaços para, através de um pseudo processo democrático de decisão coletiva, construir consensos que atendam a interesses individuais e utilitarista. Cabe, contudo, manter no horizonte que a participação não pressupõe o consenso, já que, conforme afirma Chauí (2005, p. 24), “a democracia não é o regime do consenso, mas do trabalho dos e sobre os conflitos". Ademais, como destaca Simmel (1969), é imprescindível considerar o conflito como parte da democracia, para que os espaços de negociação, muitas vezes carregados de tensão, sejam valorizados como avanços genuínos e tão importantes quanto a cooperação, pois possibilita a construção de coesão social. 
A participação, portanto, é uma temática ambígua e, por isso, requer tipificação. Nascimento (1986), de maneira simplificada, aponta para dois tipos de participação: democrática, quando permite interferência e sentidos não presumidos, ou autoritária, quando tem o intuito de legitimar posições já definidas. Ampliando esta perspectiva, Azevedo e Prates (1991) classificam a participação de duas maneiras, "restrita ou instrumental" e "ampliada ou neocorporativista". A participação restrita envolve estritamente o grupo social que será beneficiário de um projeto ou proposta. Já a participação pública ampliada está relacionada à influência, direta ou indireta, que alguns grupos sociais conseguem exercer sobre os processos de tomada de decisão.

Vianna, Cavalcanti, Cabral (2009) trazem uma terceira possibilidade de tipificação da participação, a escala de Sherry Arnstein. Criada nos Estados Unidos, em 1969, para medir participação a partir de uma hierarquia de práticas, esta escala distingue três níveis possíveis. No primeiro nível, o mais baixo, a participação não existe, restringindo-se a uma forma de manipular o apoio público através da publicidade. No segundo nível, os envolvidos são informados ou consultados, cooperando simbolicamente. O terceiro nível pressupõe parceria, delegação de poderes e controle, representando o efetivo poder dos cidadãos. As tipificações aqui apresentadas serviram de inspiração para o estabelecimento das categorias apresentadas no nosso percurso metodológico.

Há de se reconhecer os avanços significativos da participação social no processo de construção democrática em diversos segmentos, no Brasil. Entretanto, ainda existem inúmeros entraves a serem superados, entre eles a lógica que coloca o processo decisório nas mãos de técnicos, desprivilegiando a participação daqueles que não dominam o conhecimento científico, mas que são diretamente afetados pelos resultados das decisões, o que promove uma participação extremamente assimétrica (FREY, 2001).

\section{A participação dos TAE}

A comunidade acadêmica e, por consequência, a própria Universidade é composta por três corpos sociais: o corpo discente, o corpo docente e o corpo técnico-administrativo, este último mais relacionado às atividades-meio da universidade. Alberto e Balzan (2008) afirmam que os processos administrativos das áreas-meio permeiam toda a instituição universitária, sendo organizados através de cargos administrativos de instâncias e graus de responsabilidade distintos. Na Universidade, as atividades acadêmicas e administrativas coexistem e são 
A participação dos servidores técnico-administrativos na avaliação institucional: o que dizem os relatórios autoavaliação institucional

mutuamente dependentes. Portanto, o papel dos servidores TAE é fundamental e estratégico para o funcionamento dessas instituições, por isso não se pode determinar níveis de importância entre os atores institucionais.

Para Dias Sobrinho (2005, p. 30-31), a Universidade "é um espaço social em que os sujeitos sociais se formam e se constituem por intermédio de suas ações e experiências com o saber e com os outros" e, neste sentido, se configura num espaço singular para o crescimento profissional e pessoal, proporcionando também o crescimento institucional. Para contribuir efetivamente na construção deste projeto, é imprescindível que o servidor TAE sinta-se útil e importante, ou seja, parte integrante deste espaço que é a Universidade. Sendo assim, conforme apontam Alberto e Balzan (2008), se a avaliação institucional se pauta em ações voltadas à identificação dos fatores que afetam a qualidade das atividades-fim (ensino, pesquisa, e a extensão) e atividades-meio (gestão acadêmica e administrativa) da Universidade, significa que há participação dos diferentes segmentos da comunidade acadêmica e, consequentemente, a instituição estará realizando um processo dialético e dinâmico de ação-reflexão-ação "com" a comunidade, e não "para" a comunidade.

\section{Percurso metodológico}

O universo da pesquisa é composto por cinco universidades federais brasileiras, uma de cada região geográfica do Brasil, escolhidas utilizando como critérios o maior Índice Geral de Cursos (IGC) da região, e tomando como referência o IGC de 2014, por ser o resultado mais recente divulgado pelo Instituto Nacional de Estudos e Pesquisas Educacionais Anísio Teixeira (INEP). As cinco instituições selecionadas foram: a Universidade Federal do Pará (UFPA), representando a região Norte; a Universidade Federal de Pernambuco (UFPE), a região Nordeste; a Universidade de Brasília (UNB), a região Centro-Oeste; a Universidade Federal de Minas Gerais (UFMG), a região Sudeste; e a Universidade Federal do Rio Grande do Sul (UFRGS), representando a região Sul. O perfil das Instituições de Ensino Superior é apresentado no Quadro 1. 
Quadro 1 - Perfil das Universidade selecionadas para o estudo.

\begin{tabular}{|c|c|c|c|c|}
\hline UNIVERSIDADE & $\begin{array}{c}\text { ANO DE } \\
\text { FUNDAÇÃO }\end{array}$ & $\begin{array}{c}\text { NÚMERO DE } \\
\text { DOCENTES }\end{array}$ & $\begin{array}{c}\text { NÚMERO DE } \\
\text { SERVIDORES } \\
\text { TAE }\end{array}$ & $\begin{array}{c}\text { NÚMERO DE } \\
\text { DISCENTES }\end{array}$ \\
\hline UFPA & 1957 & 2.696 & 2.375 & 47.253 \\
\hline UFPE & 1946 & 2.800 & 4.233 & 45.377 \\
\hline UNB & 1961 & 2.826 & 3.122 & 49.959 \\
\hline UFMG & 1927 & 2.929 & 4.299 & 48.949 \\
\hline UFRGS & 1950 & 2.741 & 2.735 & 44.994 \\
\hline
\end{tabular}

Fonte: elaborado pelos autores a partir de informações dos relatórios de autoavaliação institucional e dos portais oficiais das IES objeto de estudo

As informações aqui discutidas são fruto de pesquisa documental, tendo como fonte os Relatórios de Autoavaliação Institucional apresentados pelas universidades selecionadas no ano de 2016, referentes ao ano/exercício 2015. Estes documentos encontram-se disponíveis para acesso no portal oficial das Comissões Próprias de Avaliação (CPA), órgão responsável por coordenar os processos internos de avaliação de cada instituição, sistematizar seus resultados e fornecer as informações solicitadas pelo INEP. Cabe informar que, embora tenhamos conhecimento da exigência de apresentação do "Relato Institucional" pelas Instituições de Ensino Superior (IES) ao INEP, eles não serão considerados para fins deste estudo por se tratar de um documento-síntese das ações e melhorias implementadas pelas IES a partir dos resultados do conjunto de avaliações, externas e internas.

Para identificar como ocorre a participação dos servidores Técnico-Administrativos em Educação (TAE) na avaliação institucional das universidades escolhidas, foram cumpridas duas etapas: levantamento de dados e categorização do conteúdo.

$\mathrm{Na}$ etapa de levantamento de dados, utilizando os descritores "servidor", "técnico", "técnico-administrativo", "funcionário", "TAE", bem como suas respectivas variações de gênero e número, foram identificados e transcritos para um arquivo do software Microsoft Excel os trechos dos relatórios onde os servidores TAE são mencionados. Em seguida, na etapa de categorização do conteúdo, os trechos transcritos foram categorizados pela perspectiva da análise categorial de conteúdo proposta por Bardin (2011), utilizando as categorias e subcategorias pré-estabelecidas, descritas no Quadro 2, tendo como inspiração as tipificações de participação apresentadas anteriormente e a partir da leitura dos Relatórios de Autoavaliação Institucional. 
A participação dos servidores técnico-administrativos na avaliação institucional: o que dizem os relatórios autoavaliação institucional

Quadro 2 - Categorias pré-estabelecidas para o estudo

\begin{tabular}{|c|c|l|}
\hline CATEGORIA & SUBCATEGORIA & \multicolumn{1}{c|}{ DESCRIÇÃO } \\
\hline \multirow{3}{*}{ PARTICIPA } & Como AVALIADOR & $\begin{array}{l}\text { Quando o servidor TAE é instado a opinar sobre os aspectos } \\
\text { avaliativos, participando de maneira simbólica. }\end{array}$ \\
\cline { 2 - 3 } & Como AVALIADO & $\begin{array}{l}\text { Quando o servidor TAE é objeto de avaliação pelo coletivo, } \\
\text { contribuindo de forma figurativa. }\end{array}$ \\
\cline { 2 - 4 } & STAKEHOLDER & $\begin{array}{l}\text { Quando o servidor TAE participa da elaboração das } \\
\text { políticas de avaliação da instituição, através da freqüência a } \\
\text { reuniões, audiências públicas, e/ou participa da análise e } \\
\text { elaboração dos relatórios, também se configurando numa } \\
\text { cooperação superficial. }\end{array}$ \\
\hline PARTICIPA & $\begin{array}{l}\text { Quando o servidor TAE é considerado como variável } \\
\text { comparativa para construção da proporcionalidade entre os } \\
\text { membros da comunidade acadêmica, ou mencionado quanto } \\
\text { à capacitação, qualificação e outros elementos que denotem } \\
\text { qualidade. Nesta categoria, o servidor TAE é utilizado como } \\
\text { instrumento para manipulação da opinião pública. }\end{array}$ \\
\hline
\end{tabular}

Fonte: elaborado pelos autores.

\section{Análise e discussão dos resultados}

Os relatórios de onde foram extraídos os dados aqui discutidos, encontrados sem qualquer dificuldade nos portais das CPAs das universidades selecionadas para o estudo, estão, de modo geral, estruturados em observância aos eixos e dimensões contemplados pelo Sinaes, a seguir indicados: Eixo 1. Planejamento e Avaliação Institucional, relativo à dimensão 8 (Planejamento e Avaliação) do Sinaes; Eixo 2. Desenvolvimento Institucional, contemplando as dimensões 1 (Missão e Plano de Desenvolvimento Institucional) e 3 (Responsabilidade Social da Instituição) do Sinaes; Eixo 3. Políticas Acadêmicas, abrangendo as dimensões 2 (Políticas para o Ensino, a Pesquisa e a Extensão), 4 (Comunicação com a Sociedade) e 9 (Políticas de Atendimento aos Discentes) do Sinaes; Eixo 4. Políticas de Gestão, compreendendo as dimensões 5 (Políticas de Pessoal), 6 (Organização e Gestão da Instituição) e 10 (Sustentabilidade Financeira) do Sinaes; Eixo 5. Infraestrutura Física, correspondente à dimensão 7 (Infraestrutura Física) do Sinaes.

A quantidade de páginas dos relatórios sofre variação de acordo com a instituição, podendo ser observados relatórios extremamente sintéticos, em contraponto a relatórios excessivamente longos. O mesmo se observa quanto à incidência dos descritores, alta em alguns relatórios, e relativamente baixa em outros, conforme podemos observar no Quadro 3. 
Quadro 3 - Relação entre número de página e ocorrência dos descritores nos relatórios de avaliação institucional das IES estudadas.

\begin{tabular}{|c|c|c|c|}
\hline UNIVERSIDADE & $\begin{array}{c}\text { NÚMERO DE } \\
\text { PÁGINAS }\end{array}$ & $\begin{array}{c}\text { TOTAL DE } \\
\text { OCORRÊNCIAS }\end{array}$ & $\begin{array}{c}\text { OCORRÊNCIAS } \\
\text { POR PÁGINA }\end{array}$ \\
\hline UFPA & 101 & 32 & 0,32 \\
\hline UFPE & 85 & 66 & 0,78 \\
\hline UNB & 120 & 88 & 0,73 \\
\hline UFMG & 16 & 4 & 0,25 \\
\hline UFRGS & 259 & 150 & 0,58 \\
\hline
\end{tabular}

Fonte: elaborado pelos autores.

\subsection{Universidade Federal do Pará (UFPA)}

A UFPA apresenta um relatório de autoavaliação institucional baseado no resultado da aplicação do questionário "Minha Opinião", instrumento avaliativo não obrigatório, composto por perguntas quantitativas e qualitativas que contemplam os cinco eixos e dez dimensões do Sinaes, direcionado a docentes, discentes e servidores TAE. O documento demonstra um nível de adesão dos servidores TAE inferior às demais categorias, com percentual de resposta ao questionário de " $34,68 \%$ dentre os discentes; $26,66 \%$ dentre os docentes e de $18,92 \%$ dentre os técnicos administrativos." (UFPA, 2016, p. 16), e traz, para além dos dados estatísticos, a transcrição de respostas dadas pelos membros da comunidade acadêmica da IES às questões propostas.

Os trechos do relatório da UFPA onde os servidores TAE são referenciados estão relacionados a todos os eixos e dimensões do Sinaes e, à luz das categorias propostas para este estudo, apontando sua participação nos papeis de AVALIADOR e AVALIADO. A construção do relatório a partir das respostas ao instrumento de autoavaliação institucional, que inclui os servidores TAE como parte do seu público respondente, fundamenta a sua atuação como AVALIADOR. Tal situação é evidenciada, por exemplo, quando o relatório aponta que " $\mathrm{Na}$ análise dos técnicos administrativos, o processo avaliativo na UFPA, foi taxado, pela maioria dos respondentes como sendo entre bom e regular." (UFPA, 2016, p. 35), e que "[...] a falta de áreas de convivência, espaços para cultura, lazer e prática de esportes [...]” (UFPA, 2016, p. 49) é a maior reclamação dos servidores TAE quando se trata de infraestrutura.

Os servidores TAE figuram também na categoria de AVALIADO no relatório de autoavaliação institucional da UFPA, pois os servidores técnico-administrativos são avaliados pela comunidade acadêmica em relação ao atendimento prestado nos diversos setores administrativos da IES, o que é demonstrado quando o relatório aponta que "Se percebe que 
A participação dos servidores técnico-administrativos na avaliação institucional: o que dizem os relatórios autoavaliação institucional

os funcionários ainda tem (sic) dificuldade para lidar com o público, porque mais de $80 \%$ das respostas esteve entre bom e regular.” (UFPA, 2016, p. 42).

Além disso, foi possível identificar o registro de sua participação na composição da CPA, bem como referências aos servidores TAE de maneira descritiva, referindo-se a dados numéricos, questões relacionadas a capacitação e qualificação, mas também sobre a importância de sua participação no processo de autoavaliação institucional, “[...] considerando o caráeter (sic) permanente de seu vínculo e a natureza de suas funções na estrutura da Universidade.” (UFPA, 2016, p. 11).

\subsection{Universidade Federal de Pernambuco (UFPE)}

Na UFPE, o relatório de autoavaliação institucional foi consolidado a partir de informações coletadas através de formulário específico, abrangendo os cinco eixos e dez dimensões do Sinaes, direcionado às pró-reitorias e órgãos suplementares. A IES também apresenta em seu relatório o resultado da avaliação do clima organizacional que, ainda que superficialmente e apenas de maneira quantitativa, aponta o grau de concordância de docentes, discentes e servidores TAE com afirmações relacionadas a gestão de ensino, pesquisa e extensão, planejamento e avaliação, desempenho e capacitação/qualificação de pessoal, infraestrutura, comunicação e segurança, aspectos estes pertinentes à autoavaliação institucional.

Os fragmentos do texto em que os servidores TAE aparecem no relatório da UFPE são relacionados a diversos aspectos da autoavaliação institucional. Analisando os trechos a partir das categorias pré-estabelecidas, não é possível encontrar evidências dos TAE figurando no papel de AVALIADOR. Embora a IES realize pesquisa de clima organizacional, tendo os servidores TAE como parte do público respondente, o instrumento utilizado trata os aspectos analisados de maneira superficial e com viés quantitativista, o que dificulta uma compreensão real da opinião dos respondentes. Além disso, foi aplicado um único instrumento às três categorias que compõem sua comunidade, desconsiderando as especificidades de cada uma delas.

Apesar de um dos aspectos tratados pelo instrumento da pesquisa de clima organizacional ser o comprometimento dos servidores TAE com as atividades de sua competência, o relatório não traz elementos que demonstrem a sua atuação no papel de AVALIADO. Além disso, o único fórum de discussão relacionado a avaliação mencionado pelo relatório é a CPA, cuja composição inclui, obrigatoriamente, o servidor TAE. 
É importante registrar que em vários momentos do seu relatório de autoavaliação institucional a UFPE trata os servidores TAE como destinatários de atividades de capacitação e qualificação, bem como de "[...] ações e projetos voltados à melhoria da qualidade de vida [...], à saúde e o bem-estar social de todos os servidores da UFPE.” (UFPE, 2016, p. 71), além de serem considerados como recursos, o que fica evidente quando o relatório aponta que

\begin{abstract}
[...] para plena realização das ações ambientais, faz-se necessário o estabelecimento de procedimentos e fluxos administrativos institucionais dotados de maior agilidade, bem como garantir a alocação dos recursos necessários para os projetos e contratos firmados e aumentar o efetivo de servidores (UFPE, 2016, p. 33).
\end{abstract}

\title{
5.3 Universidade de Brasília (UNB)
}

O relatório de autoavaliação institucional da UNB foi elaborado a partir de informações coletadas pelo Grupo Técnico de Avaliação (GTA), formado para apoiar a CPA na realização desta tarefa. Além disso, a IES desenvolve alguns projetos e processos relacionados à autoavaliação institucional; dentre estes, os que mais tem aderência ao objeto deste estudo são o AVAL e a Consulta à comunidade acadêmica. O AVAL é o Fórum de Avaliação da CPA da UnB, realizado anualmente como ferramenta de sensibilização, coleta de sugestões e feedbacks a respeito das ações de autoavaliação, com a participação de docentes, discentes e servidores TAE, além da comunidade externa. Na consulta à comunidade acadêmica, os três segmentos opinam, por meio de uma plataforma online de domínio público, sobre temas como infraestrutura, serviços, imagem da Instituição, comunicação com a sociedade e ações de capacitação.

No relatório da UNB, as passagens que fazem referência aos servidores TAE estão predominantemente relacionadas às políticas de gestão de pessoas e dizem respeito, principalmente, a questões relacionada a capacitação, qualificação, planejamento da força de trabalho e qualidade de vida, onde o servidor é destinatário das políticas, mas não participa diretamente de sua elaboração, tarefa que fica a cargo dos gestores, majoritariamente, docentes.

Não obstante o relatório aponte a realização de Consulta à Comunidade e afirme que esta possibilitou "[...] ter acesso à opinião de alunos, professores e técnico-administrativos sobre assuntos essenciais da Universidade" (UNB, 2016, p. 19), não foi possível detectar trechos que atestem a participação dos servidores TAE no papel de AVALIADOR. A IES faz referência ao registro de manifestações em relação à postura dos servidores TAE junto à Ouvidoria, bem como menciona o desenvolvimento de ferramenta informatizada para 
A participação dos servidores técnico-administrativos na avaliação institucional: o que dizem os relatórios autoavaliação institucional

avaliação de desempenho e acompanhamento de estágio probatório, mas não fornece elementos que corroborem a sua atuação no perfil de AVALIADO.

Na UNB, além de comporem a CPA e possuirem assento nas instâncias deliberativas da instituição, os servidores TAE também participam de fóruns destinados à discussão de temas importantes para a avaliação na Universidade, como o AVAL, o que constata a sua atuação como STAKEHOLDER e fica evidenciado no trecho a seguir:

\begin{abstract}
No dia 30 de setembro de 2015, foi realizada a $2^{\text {a }}$ edição do AVAL, que contou com a participação de 81 membros da comunidade universitária, entre professores (48), alunos (13), servidores técnico-administrativos (19) e da comunidade externa (1). No evento foram discutidos temas importantes para a avaliação na Universidade, tais como: avaliação externa de cursos, retenção e evasão na UnB e ENADE (UNB, 2016, p. 28).
\end{abstract}

Contudo, merecem nossa atenção as numerosas situações em que o relatório de autoavaliação institucional da UNB traz os servidores TAE sendo considerados de maneira descritiva, como integrantes da população ou destinatários de ações de gestão, em referência ao provimento de mão de obra, com a "[...] substituição de $100 \%$ do quadro de colaboradores contratados em situação de precarização por servidores efetivos no quadro da Universidade de Brasília, via concurso público[...]" (UNB, 2016, p. 50), como também na ênfase às ações de capacitação e qualificação e ao nível de qualificação da categoria, bem ilustrado no trecho a seguir:

No caso de servidores técnico-administrativos, de 2014 para 2015 registrou-se aumento de 93 servidores com título de mestre, o que corresponde a um incremento de 67,70\% neste nível de titulação e um aumento de 16 servidores com título de doutor, o que corresponde a um incremento de 36,4\% (UNB, 2016, p. 97).

\title{
5.4 Universidade Federal de Minas Gerais (UFMG)
}

A UFMG apresenta um relatório de autoavaliação institucional sintético e apontado como parcial, entretanto, até a conclusão deste estudo um relatório integral não havia sido disponibilizado pela IES. Embora o documento aponte a realização de eventos destinados a discutir a autoavaliação institucional e a criação de grupos de trabalho para a sistematização das informações destinadas ao relatório, não fica claro para o leitor a metodologia utilizada para a sua construção. Além disso, as informações apresentadas no relatório são superficiais e não viabilizam uma análise mais robusta.

Ainda assim, a utilização dos descritores permitiu identificar alguns momentos em que os servidores TAE da UFMG são mencionados no texto do relatório, aparentemente sem participação efetiva. $\mathrm{O}$ documento considera este segmento principalmente em relação a sua 
participação na composição da CPA, que eles afirmam ter sido “[...] pensada visando a representatividade da comunidade acadêmica (professores de diferentes áreas do conhecimento, servidores técnico-administrativos e estudantes), assim como a articulação (sic) setores essenciais no processo avaliativo [...]”" (UFMG, 2016, p. 13). Além disso, um único trecho aduz, de maneira descritiva, à importância da visão dos servidores TAE ligados à Pró-Reitoria de Planejamento e Desenvolvimento (Proplan) sobre as questões relacionadas à infraestrutura da IES.

\subsection{Universidade Federal do Rio Grande do Sul (UFRGS)}

A UFRGS organizou seu relatório de autoavaliação institucional de acordo com as dez dimensões estabelecidas pelo Sinaes, e a partir de dados fornecidos pelos Órgãos da Administração Central da IES. O relatório aponta ainda que

Foram construídos questionários de avaliação com perguntas fechadas e abertas, direcionadas aos diferentes segmentos da comunidade universitária: docentes, técnico-administrativos, estudantes, diferentes setores acadêmicos e administrativos, além de consultas às associações e sindicatos representativos da nossa comunidade (UFRGS, 2016, p. 22).

O relatório da UFRGS cita os servidores TAE muitas vezes, em fragmentos relacionados a todas as dimensões do Sinaes. É possível identificar a participação do segmento na condição de AVALIADOR, por exemplo, quando o relatório afirma que:

Para a obtenção da percepção da comunidade UFRGS foram identificados quatro perfis de respondentes: docentes, discentes, técnico-administrativos e coletivos (associações, sindicatos, etc.) o que permitiu a criação de quatro questionários dirigidos para cada público-alvo, com perguntas abertas e fechadas (UFRGS, 2016, p. 22).

Também é possível considerar a participação dos servidores TAE da UFRGS no papel de AVALIADO, já que afirma que "Os relatórios continham dados quantitativos e qualitativos das avaliações de condições de trabalho, bem como dados quantitativos das avaliações referentes aos servidores, chefias e equipes.” (UFRGS, 2016, p. 170). O relatório assevera que "em cada órgão da estrutura administrativa há representantes do corpo docente, discente e técnico-administrativo" (UFRGS, 2016, p. 179), o que cumpre uma determinação formal, mas não aponta a participação dos servidores TAE em fóruns destinados à ampla discussão de temas importantes para a avaliação na Universidade, envolvendo toda a comunidade acadêmica. 
A participação dos servidores técnico-administrativos na avaliação institucional: o que dizem os relatórios autoavaliação institucional

Contudo, cabe considerar a maneira frequente com que os servidores TAE da UFRGS são citados em pontos do relatório que tratam sobre a insuficiência do número de servidores, “[...] apesar da expansão das vagas oportunizadas por meio do Programa de Apoio aos Planos de Reestruturação e Expansão das Universidades Federais (REUNI) [...]” (UFRGS, 2016, p. 165), ações de promoção de qualidade de vida e integração de servidores TAE e seus dependentes, além da ênfase às práticas de capacitação e qualificação e do enaltecimento ao nível de qualificação, afirmando que "Dos técnico-administrativos, 62\% possuem nível superior e, destes, 14\% possuem pós-graduação strictu sensu." (UFRGS, 2016, p. 165).

O Quadro 4 traz a síntese da análise dos relatórios a partir das categorias préestabelecidas para este estudo, proporcionando uma visão geral dos resultados encontrados.

\section{Quadro 4 - Resumo das referências aos servidores TAE nos relatórios de autoavaliação institucional das IES estudadas, à luz das categorias pré-estabelecidas}

\begin{tabular}{|c|c|c|c|c|}
\hline \multirow{2}{*}{ UNIVERSIDADE } & \multicolumn{3}{|c|}{ PARTICIPA } & \multirow{2}{*}{ NÃO PARTICIPA } \\
\cline { 2 - 4 } & AVALIADOR & AVALIADO & STAKEHOLDER & \\
\hline UFPA & $\mathrm{X}$ & $\mathrm{X}$ & - & X \\
\hline UFPE & - & - & - & - \\
\hline UNB & - & - & $X$ & $X$ \\
\hline UFMG & - & - & - & - \\
\hline UFRGS & $\mathrm{X}$ & $\mathrm{X}$ & - & $\mathrm{X}$ \\
\hline
\end{tabular}

Fonte: elaborado pelos autores.

\section{Considerações Finais}

Mais de uma década depois da implementação do Sinaes, o presente estudo se propôs a compreender de que maneira ocorre a participação dos servidores Técnico-Administrativos em Educação (TAE) no processo de avaliação institucional das universidades federais brasileiras, a partir da análise dos Relatórios de Autoavaliação Institucional apresentados pelas Comissões Próprias de Avaliação (CPA) da UFPA, da UFPE, da UNB, da UFMG e da UFRGS. O resultado da análise dos relatórios de autoavaliação demonstrou que, apesar de ser possível constatar a existência de participação dos servidores Técnico-Administrativos em Educação (TAE) na avaliação institucional das universidades escolhidas, esta participação ainda é tímida, não abrange todas as categorias estabelecidas para este estudo e nem alcança todas as IES.

De todas as IES estudadas, apenas a UFPA e a UFRGS apontam a participação dos servidores TAE na condição de AVALIADOR, embora quatro delas (UFPA, UFPE, UNB e 
UFRGS) utilizem instrumentos que pretendem mensurar, de alguma forma, a percepção deste seguimento da comunidade acadêmica sobre as dimensões da avaliação institucional. Merece destaque o relatório da UFPA que, diferente da UFRGS, além de mencionar os servidores TAE como integrantes do público-alvo da sua consulta e, no máximo, apresentar dados quantitativos obtidos a partir desta, sistematizou seu relatório a partir das informações obtidas com o resultado da aplicação de seu questionário. Além disso, traz, ao longo do relatório, as contribuições apresentadas pelos respondentes nas perguntas dissertativas.

Também os relatórios da UFPA e UFRGS são os únicos onde os servidores TAE figuram na condição de AVALIADO, os demais utilizam processos administrativos para suprir a falta da avaliação institucional, se atendo a aspectos relacionados a avaliação de estágio probatório e avaliação de desempenho para fins de progressão, apesar de em seus instrumentos de consulta à comunidade trazerem questões que tratam do desempenho deste segmento no exercício de suas funções.

Como já era esperado, já que o Sinaes estabelece que as CPAs devem ser compostas, obrigatoriamente, por representantes dos segmentos docente, discente e técnicoadministrativo, todas as IES estudadas reforçam a presença dos servidores TAE nesta comissão. Contudo, somente a UNB dá destaque à realização anual de evento que tem o objetivo de sensibilizar a comunidade e coletar sugestões e feedbacks a respeito das ações de autoavaliação institucional, o Fórum de Avaliação da CPA da UnB (AVAL), evidenciando a participação do servidor TAE na condição de STAKEHOLDER. As demais IES, embora indiquem a participação dos TAE na composição da CPA, não apresentam em seus relatórios dados que evidenciem a sua efetiva participação.

A análise do material demonstra um perceptível esforço das IES em, se não proporcionar uma efetiva participação dos servidores TAE no processo de autoavaliação institucional, ao menos demonstrá-la em seus relatórios, o que justifica a constância com que são mencionados. Não obstante parte das IES mencionem a participação dos servidores TAE na condição de AVALIADOR, AVALIADO e/ou STAKEHOLDER, é importante considerar que ainda há uma ênfase dos relatórios ao caráter descritivo desta participação, com especial atenção a questões relacionadas a provimento de mão-de-obra, capacitação e qualificação, o que sugere que a participação dos TAE nos processos de avaliação institucional é muito pequena.

Merece atenção o fato de apenas a UFPA apresentar dados sobre a adesão dos servidores TAE ao processo de avaliação interna, mesmo com um percentual baixo de respondentes ao questionário $(18,92 \%)$, tanto em relação ao total de pessoas aptas a 
A participação dos servidores técnico-administrativos na avaliação institucional: o que dizem os relatórios autoavaliação institucional

responder, quanto em relação aos demais segmentos da comunidade acadêmica $(34,68 \%$ dentre os discentes e 26,66\% dentre os docentes). Além disso, vale observar que nenhuma das instituições faz menção à atuação das entidades representativas na sensibilização e garantia de participação dos servidores TAE no processo avaliativo. Tais questões nos levam a refletir se uma possível ausência de envolvimento da categoria se deve exclusivamente à inabilidade das IES em realizar uma avaliação efetivamente participativa, ou à falta de compreensão por parte dos servidores TAE sobre a extrema importância da avaliação institucional e seu potencial de contribuir na construção de uma universidade com mais qualidade, que ofereça melhores condições de vida e trabalho às categorias que a compõe, e que cumpra seu papel diante da sociedade.

Outra questão que, embora não tenha relação direta com o presente estudo, chama atenção é a ênfase dada ao desempenho das IES e de seus cursos em rankings nacionais e internacionais, bem como a preocupação demonstrada em envidar esforços para identificar e melhorar indicadores que exerçam impacto sobre esses rankings, encontradas nos relatórios da UFPE e UNB. Tais ações demonstram um distanciamento destas IES dos princípios que alicerçam o modelo de avaliação instituído pelo Sinaes.

Diante de todo o exposto e com base nos resultados da pesquisa, podemos considerar que o princípio da participação, um dos pilares do Sinaes, ainda não integra efetivamente as políticas e a gestão organizacionais das Universidades, já que a, a partir da análise dos relatórios de autoavaliação institucional e à luz das categorias adotadas para este estudo, a participação atribuída aos servidores TAE restringe-se a uma contribuição simbólica e superficial, sem evidências de delegação de poder e controle aos servidores TAE, ou de sua efetiva participação no processo de tomada de decisão. Entretanto, considerando que, de acordo com Atkinson e Coffey (2004), os documentos não são retratos precisos da realidade, é possível que, ainda que não demonstrada pelos relatórios, esta participação efetivamente ocorra. Embora não contemple a complexidade do tema aqui tratado e possua limitações metodológicas, esperamos que este estudo possa contribuir nesta discussão de extrema relevância, cuja prática acadêmica se demonstrou ainda inexpressiva. 


\section{Referências}

ALBERTO, Jorge Luís Moreira; BALZAN, Newton César. Avaliação de projeto políticopedagógico pelos funcionários: espaços e representatividade. Avaliação, Campinas; Sorocaba, v. 13, n. 3, p. 745-770, nov. 2008. Disponível em: $<$ http://www.scielo.br/scielo.php?pid=S141440772008000300007\&script=sci_abstract\&tlng=pt >. Acesso em: 30 abr. 2017.

ATKINSON, Paul; COFFEY, Amanda. Analysing documentary realities. In: SILVERMAN, David. Qualitative research: theory, method and practice. 2. ed. London; Thousand Oaks; New Delhi: Sage Publications, 2004. Part. III. Cap. 4. p. 56-75.

AZEVEDO, Sérgio de; PRATES, Antônio Augusto Pereira. Planejamento participativo, movimentos sociais e ação coletiva. In: ANPOCS (Org.). Ciências sociais hoje. São Paulo: Vértice \& ANPOCS, 1991. p. 122-152.

BARDIN, Laurence. Análise de conteúdo. Lisboa: Edições 70, 2011.

BARREYRO, Gladys Beatriz; ROTHEN, José Carlos. Para uma História da Avaliação da Educação Superior Brasileira: análise dos documentos do PARU, CNRES, GERES E PAIUB. Avaliação, Campinas; Sorocaba, v. 13, n. 1, p. 31-152, mar. 2008. Disponível em: $<$ http://www.scielo.br/ scielo.php?pid=S1414$40772008000100008 \&$ script=sci_abstract\&tlng=pt>. Acesso em: 30 abr. 2017.

BRASIL. Lei no 10.861, de 14 de abril de 2004. Institui o Sistema Nacional de Avaliação da Educação Superior - Sinaes. Brasília, 2004. Disponível em: <http://www.planalto.gov.br/ ccivil_03/_ato2004-2006/2004/lei/110.861.htm>. Acesso em: 30 abr. 2017.

CHAUÍ, Marilena. Considerações sobre a democracia e os obstáculos à sua concretização. In: TEIXEIRA, Ana Claudia Chaves (Org.). Os sentidos da democracia e da participação. São Paulo: Instituto Polis, 2005.

CUNHA, Luiz Antônio. Nova reforma do ensino superior: a lógica reconstruída. Cadernos de Pesquisa, São Paulo, n. 101, p. 20-49, jul. 1997.

DEMO, Pedro. Avaliação qualitativa. Campinas: Autores Associados, 2010.

DIAS SOBRINHO, José. Avaliação Institucional: marcos teóricos e políticos. Avaliação, Campinas; Sorocaba, v. 1, n. 1, jul. 1996, p. 15-24. Disponível em: <http://periodicos.uniso. br/ojs/index.php/avaliacao/article/view/722/1516>. Acesso em: 22 maio 2017.

DIAS SOBRINHO, José. Avaliação: políticas educacionais e reformas da educação superior. São Paulo: Cortez, 2003.

DIAS SOBRINHO, José. Dilemas da educação superior no mundo globalizado: sociedade do conhecimento ou economia do conhecimento. São Paulo: Casa do Psicólogo, 2005.

FAUSTO NETO, Ana Maria Quiroga. Revivendo mecanismos autoritários: as organizações de moradores da gestão de políticas públicas. In: BARREIRA, Irlys Alencar Firmo; NASCIMENTO, Elimar Pinheiro do (Orgs). Brasil urbano: cenários da ordem e da desordem. Rio de Janeiro: Notrya; Fortaleza: Sudene; UFC, 1993. p. 17-33.

FREY, Klaus. A dimensão político-democrática nas teorias de desenvolvimento sustentável e suas implicações para a gestão local. Ambiente \& Sociedade, Campinas, v. 4, n. 9, 2001.

GADOTTI, Moacir. Prefácio. In: DEMO, Pedro. Avaliação qualitativa. Campinas: Autores Associados, 2010. 
A participação dos servidores técnico-administrativos na avaliação institucional: o que dizem os relatórios autoavaliação institucional

INSTITUTO NACIONAL DE ESTUDOS E PESQUISAS EDUCACIONAIS ANÍSIO TEIXEIRA (INEP). Sistema Nacional de Avaliação da Educação Superior (Sinaes): da concepção à regulamentação. 4. ed. ampl. Brasília: INEP, 2007. Disponível em: <http://www.publicacoes.inep.gov.br/portal/download/478>. Acesso em: 4 jun. 2017.

NASCIMENTO, Elimar Pinheiro do. Participação: entre o autoritário e o democrático. Serviço Social e Sociedade, São Paulo, v. 7, abr. 1986.

RIBEIRO, Jorge Luiz Lordelo de Sales. SINAES: o que aprendemos acerca do modelo adotado para avaliação do ensino superior no Brasil. Avaliação, Campinas; Sorocaba, v. 20, n. 1, p. 143-161, mar. 2015. Disponível em: <http://www.scielo.br/scielo.php?pid=S141440772015000100143\&script= sci_abstract\&tlng=pt $>$. Acesso em: 30 abr. 2017.

ROCHA, Juliana Dalboni; BURSZTYN, Maria Augusta. A importância da participação social na sustentabilidade do desenvolvimento local. Interações, Campo Grande, MS, v. 7, n. 11, set. 2005.

SAUL, Ana Maria. Referenciais freireanos para a prática da avaliação. Revista de Educação PUC-Campinas, Campinas, n. 25, p. 17-24, nov. 2008. Disponível em: < http://periodicos.puc-campinas.edu.br/seer/index.php/reveducacao/article/view/90/79>. Acesso em: 30 abr. 2017.

SAYAGO, Doris Aleida_Villamizar. A invenção burocrática da participação: discursos e práticas no Ceará, 2000. 210 p. Tese (Doutorado) - Universidade de Brasília (UnB), Brasília, 2000.

SIMMEL, Georg. Conflict \& the web of group-affiliations. New York: Free Press, 1969.

UNIVERSIDADE FEDERAL DA PARÁ (UFPA). Comissão Própria de Avaliação (CPA). Relatório de Autoavaliação: Autoavaliação Institucional 2016, Ano base 2015. Belém, 2016. Disponível em:

〈http://www.cpa.ufpa.br/docs/Relatório\%20Autoavaliação\%20UFPA\%202015-2016.pdf>. Acesso em: 20 fev. 2017.

UNIVERSIDADE FEDERAL DE PERNAMBUCO (UFPE). Comissão Própria de Avaliação (CPA). Relatório de Autoavaliação Institucional 2015. Recife, 2016. Disponível em: <https://www.ufpe.br/documents/589185/598804/relatrio+2015.pdf/76e7dc61-ea17-4a75a98f-34442246bfc2>. Acesso em: 20 fev. 2017.

UNIVERSIDADE DE BRASÍLIA (UNB). Comissão Própria de Avaliação (CPA). Relatório de Autoavaliação Institucional 2015. Brasília, 2016. Disponível em:

<http://www.cpa.unb.br/images/cpa/autoavaliacao/Relatrio_Autoavaliao_2015_2.pdf>.

Acesso em: 20 fev. 2017.

UNIVERSIDADE FEDERAL DE MINAS GERAIS (UFMG). Comissão Própria de Avaliação (CPA). Relatório Parcial de Autoavaliação Institucional. Belo Horizonte, 2016. Disponível em: 〈https://www.ufmg.br/dai/textos/CPA-2016_Relatorio-Parcial_Parte-1.pdf〉. Acesso em: 20 fev. 2017.

UNIVERSIDADE FEDERAL DO RIO GRANDE DO SUL (UFRGS). Comissão Própria de Avaliação (CPA). RAAI 2015: Relatório de Autoavaliação Institucional da Universidade Federal do Rio Grande do Sul. Porto Alegre, 2016. Disponível em: <http://www.ufrgs.br/cpa/publicacoes/RAAI2015.pdf>. Acesso em: 20 fev. 2017.

VIANNA, Maria Lucia Teixeira Werneck; CAVALCANTI, Maria de Lourdes; CABRAL, Marta de Pina. Participação em saúde: do que estamos falando? Sociologias, Porto Alegre, n. 
21, p. 218-251, jun. 2009. Disponível em: <http://www.scielo.br/scielo.php?script=sci_arttext \&pid=S1517-45222009000100010\&lng=pt\&nrm=iso >. Acesso em: 19 fev. 2018.

ZAINKO, Maria Amélia Sabbag. Avaliação da educação superior no Brasil: processo de construção histórica. Avaliação, Campinas; Sorocaba, v. 13, n. 3, p. 827-831, nov. 2008. Disponível em <http://www.scielo.br/scielo.php?script=sci_arttext\&pid=S1414$40772008000300012 \& \operatorname{lng}=$ pt\&nrm=iso >. Acesso em: 26 fev. 2017.

Joice da Costa Martins

${ }^{1}$ Universidade Federal da Bahia| Instituto de Humanidades, Artes e Ciências Professor Milton Santos| Programa de Pós-graduação em Estudos Interdisciplinares sobre Universidade Salvador | BA | Brasil. Contato: joicemartins.rh@gmail.com

ORCIID (iD) 0000-0002-0615-2246

Jorge Luiz Lordelo de Sales Ribeiro

${ }^{2}$ Universidade Federal da Bahia| Instituto de Humanidades, Artes e Ciências Professor Milton Santos| Programa de Pós-graduação em Estudos Interdisciplinares sobre Universidade Salvador |BA | Brasil. Contato: josales@ufba.br ORCID (iD) 0000-0002-4186-7394

Artigo recebido em 2 de julho de 2017 e aprovado em 28 de março de 2018. 